\title{
Antioxidantes producidos por microorganismos acuáticos y terrestres con uso potencial en cosméticos
}

\author{
Antioxidants produced by aquatic and terrestrial microorganisms with potential use in cosmetics
}

\author{
Zulay Abril-Ibarra ${ }^{1 *}$
}

\begin{abstract}
Resumen
Los antioxidantes son compuestos naturales o sintéticos capaces de prevenir o retardar el daño oxidativo, al contrarrestar radicales libres en biomoléculas expuestas a este tipo de estrés. La industria alimentaria, farmacéutica y cosmética ha optado por sustituir los ingredientes químicos por compuestos naturales, utilizando en gran cantidad compuestos obtenidos de plantas. Sin embargo, la mayor fuente de recursos naturales está en los microorganismos, debido a su gran diversidad y a los mecanismos metabólicos que desarrollan para adaptarse a zonas con ambientes no favorables para el desarrollo de la vida. Entre los microorganismos productores de compuestos útiles para los seres humanos que se incluyen en esta revisión se encuentran: hongos, bacterias y microalgas. Los microorganismos más explorados son los que habitan ambientes terrestres debido a la accesibilidad hacia los mismos; no obstante, el extenso ambiente marino también alberga una gran diversidad de organismos de los que se podrían obtener varios compuestos como carotenoides, flavonoides, fenoles o exopolisacáridos con aplicaciones cosméticas. En este artículo se presenta una revisión de 90 artículos publicados entre 2015 y 2020 con información relevante sobre los antioxidantes producidos por microorganismos acuáticos y terrestres con uso potencial en cosméticos, con el fin de proporcionar información significativa sobre alternativas a antioxidantes sintetizados artificialmente y obtenidos de fuentes vegetales.
\end{abstract}

Palabras claves: compuestos naturales, bacterias, estrés oxidativo, hongos, microalgas, radicales libres

\begin{abstract}
Antioxidants are natural or synthetic compounds capable of preventing or delaying oxidative damage, by counteracting free radicals in biomolecules exposed to this type of stress. The food, pharmaceutical and cosmetic industry has replaced chemical ingredients with natural compounds, using substances obtained from plants. However, the greatest source of natural resources is in microorganisms, due to their great diversity and the metabolic mechanisms they have developed to adapt to areas with unfavorable environments. The microorganisms that produce compounds useful for humans that are included in the review are: fungi, bacteria, and microalgae. The most explored microorganisms are those that inhabit terrestrial environments due to their accessibility, however the extensive marine environment also harbors a great diversity of organisms from which several compounds such as carotenoids, flavonoids, phenols or exapolysaccharides to applied in cosmetic industry. This article presents a review of 90 articles published between 2015 and 2020 with relevant information about antioxidants produced by aquatic and terrestrial microorganisms with potential use in cosmetics, to provide relevant information about alternatives to artificially or plants synthetized antioxidants.
\end{abstract}

Keywords: Natural compounds, bacteria, oxidative stress, mushrooms, microalgae, free radicals

\footnotetext{
1. Universidad Técnica de Ambato, Ecuador.

* Autor para correspondencia: <zulabril12@gmail.com>
} 


\section{INTRODUCCIÓN}

Varios fenómenos externos como la contaminación ambiental, la radiación UV, la luz azul, la concentración elevada de oxígeno y la acción de sustancias químicas provocan daños en el organismo humano debido a su elevada producción de radicales libres (RLs) como especies reactivas de oxígeno (ROS), siendo la piel el órgano más afectado (Sakthivel y Devi, 2019). Para disminuir los efectos dañinos de los RLs como el cáncer de piel, el envejecimiento prematuro de la piel, la disminución de la respuesta inmune, la pérdida de elasticidad o la perdida de pigmentación, las industrias cosméticas han incorporado antioxidantes y filtros solares, como coadyuvantes en sus productos (Mendes-Silva et al., 2020).

De acuerdo con Bianchet et al. (2020), la mayoría de los cosméticos son elaborados con sustancias químicas sintéticas y derivados del petróleo, recursos que producen residuos difíciles de degradar, por lo que constituyen un gran problema medioambiental. Además, muchas de las sustancias químicas utilizadas provocan problemas en la piel a corto y largo plazo, como irritación, daños en los fibroblastos y envejecimiento prematuro de la piel (Cottrez et al., 2020). Las tecnologías verdes se han incluido también en el desarrollo de cosméticos, por ello, las sustancias antioxidantes han ganado alto interés para la producción de cremas, geles, aceites, polvos compactos y protectores solares, entre otros (Hamidi et al., 2020).

Cosméticos con ingredientes constituyentes de plantas, animales permitidos y microorganismos, han ganado mayor demanda en el mercado mundial por lo que se busca incluir ingredientes de origen natural en categoría de antioxidantes, antimicrobianos, espesantes, agentes anti-edad y agentes para el blanqueamiento de la piel (Sugibayashi et al., 2019). Los antioxidantes juegan un rol importante dentro de los cosméticos, ya que son los encargados de evitar la peroxidación lipídica, la oxidación de proteínas y el daño en el ADN provocados por el incremento en la producción de ROS en la piel (Unsal et al., 2020).

Dada la capacidad de retrasar o prevenir significativamente la oxidación de biomoléculas orgánicas e inorgánicas, los antioxidantes obtenidos de varias sustancias naturales son muy utilizados en el campo de la medicina dentro de la formulación de antiinflamatorios, antidiabéticos, defensa ante enfermedades cardiovasculares o de neuro y hepatoprotectores; en la farmacéutica, nutraceútica y cosmética (Neha et al., 2019). Actualmente, la fuente principal de extracción de recursos antioxidantes son las plantas, ya que contienen gran cantidad de compuestos bioactivos como flavonoides, terpenos, ácidos grasos, polisacáridos, esteroles carotenoides y enzimas que presentan actividad antioxidante (Hęś et al., 2019).

Sin embargo, la recolección de células vegetales es mucho más complicada, dado que presentan ciertas restricciones, sobre todo las especies protegidas y las condiciones de crecimiento y mantenimiento son más estrictas (Atanasov et al., 2015), por lo que optar por microorganismos se ha convertido en una gran alternativa para obtener compuestos bioactivos. Los microorganismos, además, son extremadamente diversos, incluyendo bacterias, arqueas, protistas, hongos y algas, por lo que, en las últimas décadas, ha habido grandes progresos en la extracción de la inmensa diversidad biológica disponible en el mundo microbiano (Peyrat et al., 2019).

El objetivo de la presente revisión es detallar compuestos antioxidantes no tóxicos producidos por microorganismos acuáticos y terrestres para proporcionar información relevante sobre alternativas a antioxidantes sintetizados artificialmente y obtenidos de fuentes vegetales. Además, teniendo en cuenta que las investigaciones de antioxidantes producidos por microorganismos marinos o aislados de ambientes extremos están apenas emergiendo, y que su metabolismo está mejor adaptado para producir metabolitos antioxidantes, este artículo recopila información relevante que permite comparar con aquellos antioxidantes originarios de microorganismos terrestres.

\section{METODOLOGÍA}

Se revisaron 130 artículos en inglés, de los cuales se seleccionaron los más relevantes, considerando los siguientes criterios de inclusión:

- Artículos publicados durante y después de 2015 
- Artículos publicados en las siguientes bases de datos: Pro-Quest, Web of Science, Scopus, Science Direct y Springer

- Artículos que presentaban resultados de ensayos de toxicidad

- Se utilizaron palabras claves como: antioxidants, natural antioxidants, antioxidants producing microorganisms, application of natural antioxidants, activity of antioxidants, antioxidants acuatic microorganisms, synthetic antioxidants, antioxidants in cosmetics, advantages/disadvantages of microorganisms/plans, toxicity of antioxidants, phototoxicity/cytotoxicity.

La información fue esquematizada a través de tablas, una que permite comparar ventajas y desventajas entre antioxidantes de origen vegetal y de origen microbiológico; y otras tres que posibilitan evidenciar las propiedades de diferentes compuestos antioxidantes, donde se incluyó su clasificación, su actividad biológica y su utilidad en diversas ramas de la ciencia.

\section{Generalidades de antioxidantes naturales}

La actividad antioxidante que presentan los organismos vivos se desarrolló en conjunto con la atmosfera oxigénica (Kaboré et al., 2017). Esta actividad se originó como un mecanismo de defensa dentro de los organismos primitivos, ya que al empezar a captar el oxígeno por procesos de óxido-reducción se generaban especies reactivas (ROS) que al acumularse en las células eran letales y causaban daños en el ADN, lípidos y proteínas (Ndongo et al., 2020).

El oxígeno se ha mantenido como un elemento esencial para el crecimiento y desarrollo de gran parte de formas de vida, por lo que no está presente solo en el aire, si no también disuelto en el agua; lo que ha provocado que tanto organismos terrestres como acuáticos desarrollen un sistema antioxidante (Ślesak et al., 2019).

Los antioxidantes pueden ser compuestos naturales o sintéticos capaces de prevenir o generalmente retardar el daño oxidativo, ya que contrarrestan los RLs, en biomoléculas expuestas a este tipo de estrés (Bazinet y Doyen, 2015). Químicamente, los antioxidantes incluyen eliminadores o cazadores de RLs, agentes reductores, inactivadores de peróxidos o de otras especies reactivas de oxígeno, y quelantes de metales (Yang et al., 2018).

En los sistemas biológicos los antioxidantes se encargan de la protección frente a la oxidación inhibiendo la producción de RLs, capturando los RLs para evadir la cadena de reacción o restaurando el deterioro provocado por RLs (Neha et al., 2019). Los antioxidantes naturales pueden ayudar a fortalecer la inmunidad innata del cuerpo humano contra enfermedades crónicas o relacionadas con la edad, protegiendo el cuerpo humano de los efectos nocivos de los RLs, y disminuyendo así el impacto del fotoenvejecimiento de las células cutáneas (Khan y Ahmad, 2020).

Además, los antioxidantes naturales presentan ventajas frente a los antioxidantes sintéticos, ya que no influyen en la señalización y regulación de muchas vías biológicas (Ambati et al., 2019), no son tóxicos ni obstaculizan la función normal de las células humanas (Valentová, 2020). Según Shah et al., (2016), los antioxidantes sintéticos pueden causar genotoxicidad y carcinogenicidad en altas concentraciones, por lo que presentan menos propiedades que promueven la salud, incluso presentan un potencial antioxidante más bajo que los compuestos naturales; todo esto los hace menos valiosos y deseables como coadyuvantes o aditivos (Novoveská et al., 2019).

\section{Fuentes para la obtención de antioxidantes natu- rales}

Los antioxidantes naturales pueden ser de origen vegetal o compuestos derivados de otros organismos vivos con potencial de inhibir el estrés oxidativo. Estos antioxidantes naturales pueden balancear el estrés oxidativo irregular y restablecer la homeostasis celular (Ramana et al., 2018). Los más utilizados en la industria de alimentos, farmacéutica y cosmética generalmente son de origen vegetal. En los organismos vegetales los compuestos fenólicos como ácidos fenólicos, flavonoides, lignanos, estilbenos y taninos son los responsables de la actividad antioxidante; y se los pueden encontrar en semillas oleaginosas, cereales, legumbres, plantas de la familia Lamiaceae, té y café, frutos secos, frutas y bayas (Amarowicz y 
Pegg, 2019).

Los compuestos fenólicos de las plantas están asociados con el mecanismo de defensa contra patógenos invasores y la radiación y son responsables del sabor, color, olor y acidez de los alimentos. En varios estudios se ha revelado que pueden ser protectores contra la incidencia y el progreso de la diabetes, cáncer, osteoporosis, enfermedades cardiovasculares y neurodegenerativas (Pengkumsri et al., 2019), por ello son de especial interés para la industria de alimentos, fármacos, cosméticos e incluso para la producción de plásticos (Khan y Ahmad, 2020).

Los antioxidantes obtenidos de plantas han sido aplicados en varios productos de interés humano desde hace algunos años; sin embargo, existen otros organismos vivos capaces de producir sustancias con capacidades antioxidantes similares, los microorganismos (Ceylan et al., 2019). Las sustancias antioxidantes de estos pequeños organismos presentan incluso más ventajas frente a las sustancias producidas por las plantas (Penchaszadeh, 2017), por lo que los microorganismos son una fuente de compuestos antioxidantes de gran interés. La tabla 1 presenta las ventajas y desventajas de los antioxidantes de origen vegetal y de origen microbiológico.

Los microorganismos son una amplia fuente de nuevas sustancias químicas que representan un valioso recurso para innovar en biotecnología (Mendes-Silva et al., 2020). Aunque por la accesibilidad se han investigado y utilizado con mayor frecuencia los microorganismos terrestres y de ecosistemas de agua dulce, los organismos que presentan mayor ventaja en la producción de metabolitos son los que habitan en ecosistemas marinos (Hamidi et al., 2020), debido a la enorme diversidad biológica y capacidad para sintetizar metabolitos secundarios bioactivos (Pedroso et al., 2019).

El ecosistema marino cubre alrededor de tres cuartos de la superficie terrestre y todo el volumen de agua, así como el suelo marino es ocupado por organismos vivos (Peyrat et al., 2019), por lo que hay una amplia gama de microrganismos marinos que han desarrollado estrategias inteligentes para adaptarse y crecer (Hamidi et al., 2020).
Las diferencias en la presión, temperatura, variaciones en las propiedades espectrales en la luz y la movilidad del medio en el que se encuentran los organismos, han provocado que las rutas metabólicas de los microorganismos marinos sean más variadas (Baker et al., 2020). Además, la contaminación afecta de manera directa a los ecosistemas terrestres, por lo que se pueden presentar modificaciones tóxicas en los metabolitos producidos por microorganismos ( $\mathrm{Ri}-$ bera, 2019) y el crecimiento de los microorganismos útiles que habitan en los mismos se limita a una capa de un metro de espesor, debido a las limitaciones de carbono y nitrógeno (Soong et al., 2020). Por ello, las propiedades de los microorganismos marinos hacen que sus moléculas sean de gran interés para incluir en varios productos y procesos industriales.

\section{Microorganismos generadores de antioxidantes con potencial cosmético}

Actualmente, la industria cosmética, al igual que otros sectores industriales, ha optado por tecnologías verdes. Por lo anterior, los cosméticos ahora producidos presentan una composición natural y orgánica (Bianchet et al., 2020). Los productos cosméticos son de uso externo para la piel, rostro, uñas, cavidad bucal y cabello; y su toxicidad debe ser evaluada a través de ensayos con dosis repetidas de toxicidad o ensayos de biocinética y carcinogenicidad, en células animales o células de tejidos humanos, ya que se incluyen conservantes, agentes antimicrobianos, biosurfactantes, fragancias, etc., que pueden dañar las células del cuerpo (Rogiers et al., 2020).

El efecto tóxico de los cosméticos es reducido al incorporar en los procesos de producción moléculas de origen natural como antioxidantes naturales, tales como alcaloides, quinonas, furanones, piraones, benzopiroides, xantonas, terpenos, esteroides, péptidos y compuestos fenólicos (Agrawal et al., 2020). Los compuestos bioactivos con actividad antioxidante son producidos por la mayoría de los organismos sean procariontes o eucariontes. Los microorganismos como bacterias, arqueas o eucariontes (hongos), son fuentes valiosas de compuestos antioxidantes y pueden ser utilizados en beneficio de la humanidad, siendo útiles en aplicaciones biotecnológicas, industrias farmacéuticas, de alimentos y cosméticas 
(Chandra et al., 2020).

Tanto microorganismos terrestres, como de ecosistemas de agua dulce y marinos son una fuente rica de compuestos antioxidantes, ya que presentan una diversidad biológica enorme y una gran capacidad para sintetizar metabolitos secundarios bioactivos (Pedroso et al., 2019). Las tablas 2, 3 y 4 presentadas a continuación incluyen diferentes tipos de antioxi- dantes producidos por estos microorganismos.

Todos los compuestos antioxidantes recopilados en las (tablas 2, 3 y 4) fueron seleccionados después comprobar la existencia de evidencia bibliográfica sobre su toxicidad en animales o en células humanas. Además, el $80 \%$ de los compuestos presentan resistencia o capacidad de absorber la radiación UV. La radiación UV causa daños en la piel, como eritema

Tabla 1. Ventajas y desventajas de los antioxidantes de origen vegetal y de origen microbiológico

\begin{tabular}{|c|c|c|}
\hline Origen de los antioxidantes & Ventajas & Desventajas \\
\hline \multirow{4}{*}{ Antioxidantes de origen vegetal } & $\begin{array}{l}\text { Las células se pueden cultivar } \\
\text { individualmente, como si fueran } \\
\text { microorganismos (Hidalgo et al., } \\
\text { 2018). }\end{array}$ & $\begin{array}{l}\text { Las células de origen vegetal son } \\
\text { delicadas, por lo que demandan } \\
\text { condiciones más costosas de } \\
\text { mantenimiento (Zhang et al., 2020). } \\
\text { La recolección del material vegetal, } \\
\text { es más compleja, ya que el hábitat } \\
\text { de las plantas, en particular de las } \\
\text { especies protegidas, debe respetarse } \\
\text { de acuerdo a la normatividad vigente } \\
\text { relacionada (Atanasov et al., 2015). }\end{array}$ \\
\hline & \multirow{3}{*}{$\begin{array}{l}\text { Pueden cultivarse en biorreactores } \\
\text { a gran escala para la producción de } \\
\text { compuestos valiosos para la industria } \\
\text { químico farmacéutica (Hidalgo et al., } \\
\text { 2018). }\end{array}$} & $\begin{array}{l}\text { La biosíntesis de componentes } \\
\text { activos en la planta se limita a un } \\
\text { órgano específico o a la formación de } \\
\text { estructuras, por lo que su producción } \\
\text { se basa en cultivos de órganos para } \\
\text { su localización (Hidalgo et al., 2018). }\end{array}$ \\
\hline & & $\begin{array}{l}\text { La síntesis de ciertos compuestos } \\
\text { depende de interacciones con } \\
\text { microorganismos (Lutzu \& Dunford, } \\
\text { 2018). }\end{array}$ \\
\hline & & $\begin{array}{l}\text { La generación de mezclas de } \\
\text { componentes activos requiere de } \\
\text { más pasos para producir el producto } \\
\text { final, tiene bajo rendimiento y alto } \\
\text { costo (Soares et al., 2017). }\end{array}$ \\
\hline \multirow{4}{*}{ Antioxidantes de origen microbiológico } & $\begin{array}{l}\text { Los metabolitos y enzimas que se } \\
\text { obtienen de los microorganismos son } \\
\text { mucho más variados y adaptados a } \\
\text { ambientes extremos (Satoh \& Oono, } \\
\text { 2019) }\end{array}$ & $\begin{array}{l}\text { Las tecnologías de procesamiento } \\
\text { son costosas debido a que varios } \\
\text { compuestos no muestran estudios } \\
\text { previos (Mussagy et al., 2019). }\end{array}$ \\
\hline & $\begin{array}{l}\text { Permiten mayor eficiencia y rapidez } \\
\text { para obtener compuestos a escala } \\
\text { industrial (Bianchet et al., 2020) }\end{array}$ & $\begin{array}{l}\text { El porcentaje de microorganismos } \\
\text { cultivables en laboratorio es menor al } \\
2 \% \text { (Lutzu \& Dunford, 2018). }\end{array}$ \\
\hline & $\begin{array}{l}\text { El bioprocesamiento de los com- } \\
\text { puestos activos puede controlarse, } \\
\text { aumentando los rendimientos de } \\
\text { producción y reduciendo los costos } \\
\text { (Mussagy et al., 2019) }\end{array}$ & \multirow{2}{*}{$\begin{array}{l}\text { Las nuevas cepas requieren ser } \\
\text { caracterizadas y almacenadas } \\
\text { manteniendo sus características } \\
\text { particulares, lo cual resulta costoso } \\
\text { (Lutzu \& Dunford, 2018). }\end{array}$} \\
\hline & $\begin{array}{l}\text { No generan micromoléculas difíciles } \\
\text { de degradar (Bianchet et al., 2020) }\end{array}$ & \\
\hline
\end{tabular}


Tabla 2. Antioxidantes producidos por microorganismos terrestres con uso potencial en cosméticos

\begin{tabular}{|c|c|c|c|c|c|}
\hline $\begin{array}{l}\text { Compuesto antioxi- } \\
\text { dante }\end{array}$ & $\begin{array}{l}\text { Tipo de compu- } \\
\text { esto/Clasificación }\end{array}$ & $\begin{array}{l}\text { Clasificación del micro- } \\
\text { organismo (Reino; divi- } \\
\text { sión/filo especie) }\end{array}$ & Actividad biológica de la sustancia & Utilidad & Fuente \\
\hline $\begin{array}{l}\text { Hexahidropirrolizin- } \\
\text { 3-ona }\end{array}$ & Alcaloide & $\begin{array}{l}\text { Hongo; Ascomycota; } \\
\text { Botryosphaeria dothidea }\end{array}$ & $\begin{array}{l}\text { Acción fisiológica pronunciada y } \\
\text { biológicamente activos en señalizaciones } \\
\text { antimicrobianas y antiinflamatorias }\end{array}$ & $\begin{array}{l}\text { Usado como antimicrobiano } \\
\text { y antiinflamatorio }\end{array}$ & $\begin{array}{l}\text { (Pedroso et al., } \\
\text { 2019; Prakash et al., } \\
\text { 2019) }\end{array}$ \\
\hline \multirow[b]{2}{*}{ Ácido terreico } & \multirow[b]{2}{*}{ Epóxido } & $\begin{array}{l}\text { Hongo; Ascomycota; } \\
\text { Aspergillus Terreus LS01 }\end{array}$ & \multirow{2}{*}{$\begin{array}{l}\text { Inhibidor covalente de la enzima } \\
\text { biosintética MurA de la pared celular } \\
\text { bacteriana. }\end{array}$} & \multirow{2}{*}{$\begin{array}{l}\text { Usado en la industria } \\
\text { farmacéutica por sus } \\
\text { propiedades antibióticas. }\end{array}$} & (Yin et al., 2016) \\
\hline & & $\begin{array}{l}\text { Hongo; Ascomycota; } \\
\text { Pseudocercospora sp. } \\
\text { ESL } 02\end{array}$ & & & $\begin{array}{l}\text { (Prihantini \& } \\
\text { Tachibana, 2017) }\end{array}$ \\
\hline $\begin{array}{l}\text { Ácido 6- } \\
\text { metilsalicílico }\end{array}$ & $\begin{array}{l}\text { Compuesto } \\
\text { orgánico }\end{array}$ & $\begin{array}{l}\text { Hongo; Ascomycota; } \\
\text { Pseudocercospora sp. } \\
\text { ESL } 02\end{array}$ & $\begin{array}{l}\text { Mejora la acumulación de proteínas } \\
\text { relacionadas con la patogénesis }\end{array}$ & $\begin{array}{l}\text { Utilizado para mejorar la } \\
\text { acumulación de proteínas } \\
\text { relacionadas con la } \\
\text { patogénesis y en estudios } \\
\text { de resistencia al virus del } \\
\text { mosaico del tabaco } \\
\end{array}$ & $\begin{array}{l}\text { (Prihantini \& } \\
\text { Tachibana, 2017) }\end{array}$ \\
\hline $\begin{array}{l}\text { Xilo y arabinoxil } \\
\text { ooligosacáridos }\end{array}$ & $\begin{array}{l}\text { Carbohidrato } \\
\text { polimérico }\end{array}$ & \begin{tabular}{ll|} 
Mónera; & Firmicutes; \\
Bacillus & safensis \\
CBLMA18 & \\
\end{tabular} & $\begin{array}{l}\text { Antioxidante. Sintetizadas a partir de } \\
\text { un metabolismo alterno para protección } \\
\text { contra radicales libres }\end{array}$ & Industria de alimentos & $\begin{array}{l}\text { (Bouiche et al., } \\
\text { 2020) }\end{array}$ \\
\hline Resveratrol & $\begin{array}{l}\text { Flavonoide } \\
\text { polifenólico }\end{array}$ & $\begin{array}{l}\text { Hongo; Ascomycota; } \\
\text { Arcopilus aureus }\end{array}$ & $\begin{array}{l}\text { Antioxidante con fuerte actividad } \\
\text { antifúngica, así como actividad anti- } \\
\text { estafilocócica. Neutraliza e inhibe la } \\
\text { formación de especies reactivas de } \\
\text { oxígeno. Contrarresta la peroxidación } \\
\text { de lípidos y la oxidación de proteínas. } \\
\text { Inhibe la actividad inducible de óxido } \\
\text { nítrico sintasa (iNOS) y la síntesis de } \\
\text { tromboxano A2 en leucocitos }\end{array}$ & $\begin{array}{l}\text { Mercado cosmético y } \\
\text { farmacéutico (reduciendo } \\
\text { la progresión de enfer- } \\
\text { medades neurológicas). } \\
\text { Producción de ácidos } \\
\text { orgánicos, antibióticos, } \\
\text { aminoácidos y vitaminas } \\
\text { comercialmente }\end{array}$ & $\begin{array}{l}\text { (Dwibedi \& Saxena, } \\
\text { 2018; Dwibedi \& } \\
\text { Saxena, 2020) }\end{array}$ \\
\hline Ácido gálico & Ácido fenólico & $\begin{array}{l}\text { Hongo; Ascomycota; } \\
\text { Achaetomium sp. }\end{array}$ & $\begin{array}{l}\text { Potencial antioxidantes con un papel } \\
\text { vital como agente reductor, silenciador } \\
\text { de singletes de oxígeno y donante de } \\
\text { hidrógeno }\end{array}$ & Industria farmacéutica & $\begin{array}{l}\text { (Uma Anitha \& } \\
\text { Mythili, 2017) }\end{array}$ \\
\hline$\beta$-caroteno & & & & $\begin{array}{l}\text { Usados en la industria } \\
\text { farmacéutica por su acti- }\end{array}$ & \\
\hline Toruleno & Carotenoides & $\begin{array}{l}\text { Hongo; Basidiomycota; } \\
\text { Rhodotorula mucilagi- } \\
\text { nosa }\end{array}$ & $\begin{array}{l}\text { Capturan radicales de peroxilo, inhiben } \\
\text { la degradación por singlete de oxígeno, e } \\
\text { inhiben la peroxidación de los lípidos. }\end{array}$ & $\begin{array}{l}\text { vidad anticancerígena, en } \\
\text { suplementos dietéticos, } \\
\text { agentes colorantes ali- }\end{array}$ & $\begin{array}{l}\text { (Cheng \& Yang, } \\
\text { 2016), (Kot et al., } \\
\text { 2018) }\end{array}$ \\
\hline Torularhodin & & & & & \\
\hline
\end{tabular}




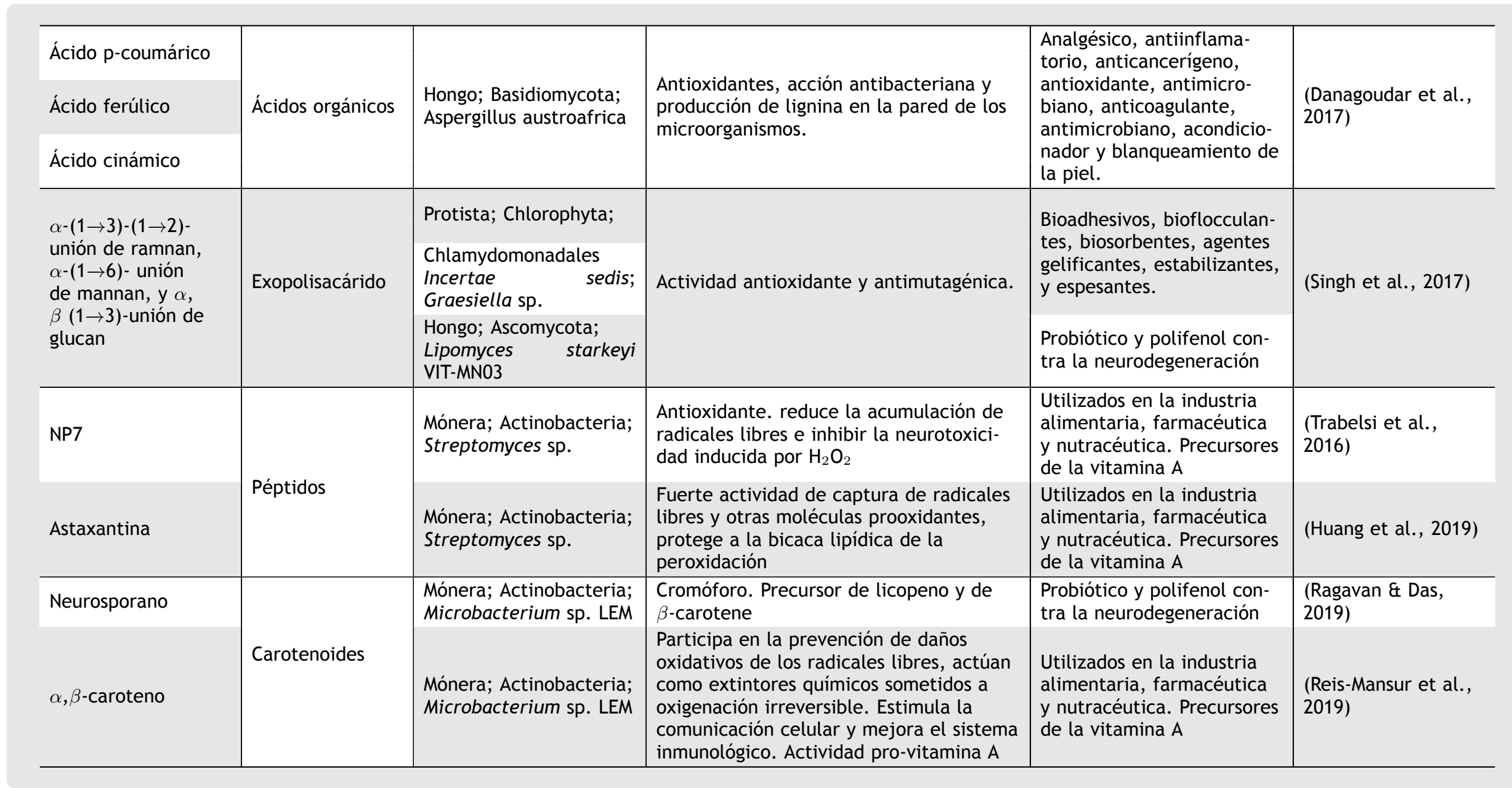


Tabla 3. Antioxidantes producidos por microorganismos de ecosistemas de agua dulce con uso potencial en cosméticos

\begin{tabular}{|c|c|c|c|c|c|}
\hline $\begin{array}{l}\text { Compuesto antioxi- } \\
\text { dante }\end{array}$ & $\begin{array}{l}\text { Tipo de compu- } \\
\text { esto/Clasificación }\end{array}$ & $\begin{array}{l}\text { Clasificación del micro- } \\
\text { organismo (Reino; divi- } \\
\text { sión/filo especie) }\end{array}$ & Actividad biológica de la sustancia & Utilidad & Fuente \\
\hline Ácido clorogénico & \multirow[t]{2}{*}{ Ácidos orgánicos } & \multirow[t]{2}{*}{$\begin{array}{l}\text { Mónera; Cyanobacteria; } \\
\text { Fortieaceae; Aulosira } \\
\text { fertilissima }\end{array}$} & \multirow[t]{2}{*}{$\begin{array}{l}\text { Antioxidante, protección contra } \\
\text { desoxirribosa. Efecto inhibidor sobre } \\
\text { bacterias, actividad multi-antivirales y } \\
\text { efecto antifúngico }\end{array}$} & $\begin{array}{l}\text { Utilizado en comida, } \\
\text { cosméticos y medicinas, } \\
\text { especialmente en } \\
\text { medicinas chinas }\end{array}$ & (Wang et al., 2020) \\
\hline Ácido cafeico & & & & Aplicaciones farmacéuticas & $\begin{array}{l}\text { (Trabelsi et al., } \\
\text { 2016) }\end{array}$ \\
\hline Extracto metanólico & & $\begin{array}{l}\text { Mónera; Proteobacteria; } \\
\text { Novosphingobium sp. } \\
\text { PP1Y }\end{array}$ & $\begin{array}{l}\text { Participa en el sistema de eliminación } \\
\text { reactiva de oxígeno para preservar la } \\
\text { homeostasis redox celular }\end{array}$ & Industria biotecnológica & (Petruk et al., 2019) \\
\hline Escualeno & Hidrocarburo & $\begin{array}{l}\text { Mónera; Cyanobacteria; } \\
\text { Phormidium autumnale }\end{array}$ & $\begin{array}{l}\text { Actividad antioxidante. Precursor de } \\
\text { colesterol y de esteroles }\end{array}$ & $\begin{array}{l}\text { Agroindustria y en la } \\
\text { industria alimentaria }\end{array}$ & $\begin{array}{l}\text { (Fagundes et al., } \\
\text { 2019) }\end{array}$ \\
\hline Ácido ferúlico & $\begin{array}{l}\text { Compuesto } \\
\text { fenólico }\end{array}$ & $\begin{array}{l}\text { Mónera; Cyanobacteria; } \\
\text { Cronbergia siamensis, } \\
\text { Sphaerospermopsis } \\
\text { aphanizomenoides } \\
\text { (KU212886.1) }\end{array}$ & $\begin{array}{l}\text { Exhibe una fuerte actividad antioxidante } \\
\text { a través de la donación de un átomo de } \\
\text { hidrógeno de su grupo hidroxilo fenólico }\end{array}$ & $\begin{array}{l}\text { Aplicaciones en los } \\
\text { sectores farmacéutico y } \\
\text { cosmético }\end{array}$ & (Badr et al., 2019) \\
\hline
\end{tabular}

Tabla 4. Antioxidantes producidos por microorganismos marinos con uso potencial en cosméticos

\begin{tabular}{|c|c|c|c|c|c|}
\hline $\begin{array}{l}\text { Compuesto antioxi- } \\
\text { dante }\end{array}$ & $\begin{array}{l}\text { Tipo de compu- } \\
\text { esto/Clasificación }\end{array}$ & $\begin{array}{l}\text { Clasificación del micro- } \\
\text { organismo (Reino; filo; } \\
\text { especie) }\end{array}$ & Actividad biológica de la sustancia & Utilidad & Fuente \\
\hline \multirow[t]{2}{*}{$\begin{array}{l}\text { Ácido docosahexae- } \\
\text { noico (DHA) }\end{array}$} & \multirow[t]{2}{*}{ Ácido graso } & $\begin{array}{l}\text { Protista; Heterokonta; } \\
\text { Schizochytrium } \\
\text { sp.(Microalga) }\end{array}$ & $\begin{array}{l}\text { Actividad antioxidante que evita la } \\
\text { acumulación de altos niveles de ROS } \\
\text { causados por la peroxidación lipídica } \\
\text { y previene la pérdida de los lípidos } \\
\text { producidos }\end{array}$ & $\begin{array}{l}\text { Aditivo alimentario y } \\
\text { uso farmacéutico (como } \\
\text { antioxidante en el cerebro) }\end{array}$ & (Sun et al., 2018) \\
\hline & & $\begin{array}{l}\text { Protista;-; Auranti- } \\
\text { ochytrium sp. T66 } \\
\text { (Microalga) }\end{array}$ & Actividad antiinflamatoria y antioxidante & Nutracéutico & (Patel et al., 2019) \\
\hline Escualeno & Hidrocarburo & $\begin{array}{l}\text { Protista;-; Auranti- } \\
\text { ochytrium sp. T66 } \\
\text { (Microalga) }\end{array}$ & $\begin{array}{l}\text { Actividad antioxidante, precursor } \\
\text { de miles de compuestos bioactivos, } \\
\text { incluyendo esteroles y hopanoides }\end{array}$ & $\begin{array}{l}\text { Industria cosmética, } \\
\text { farmacéutica (efecto } \\
\text { positivo sobre la respuesta } \\
\text { inmune), y adyuvante para } \\
\text { aumentar la capacidad de } \\
\text { respuesta inmune a las } \\
\text { vacunas }\end{array}$ & (Patel et al., 2019 \\
\hline
\end{tabular}




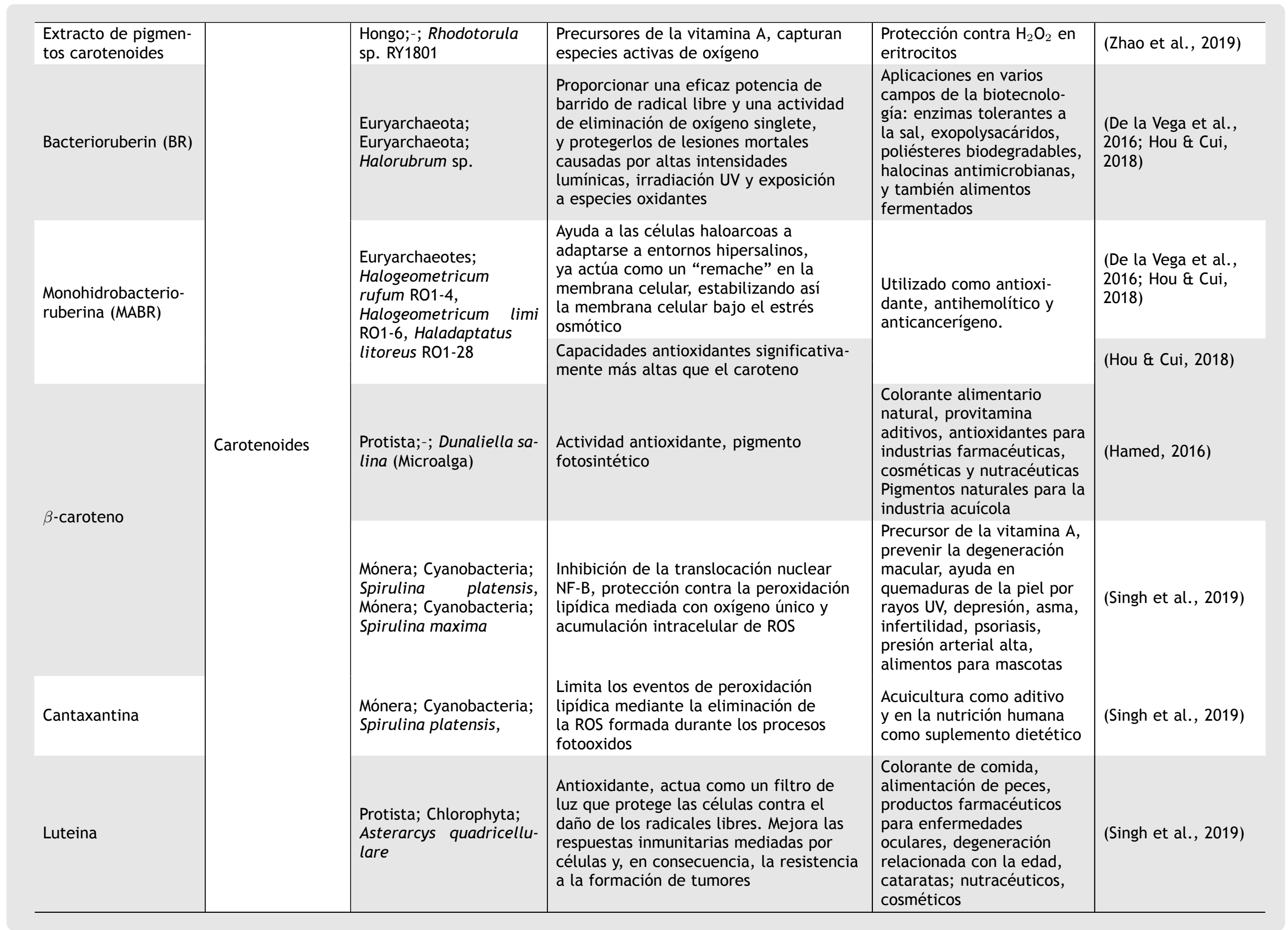




\begin{tabular}{|c|c|c|c|c|c|}
\hline Astaxantina & & $\begin{array}{l}\text { Protista; Chlorophyta } \\
\text { Asterarcys quadricellu- } \\
\text { lare }\end{array}$ & $\begin{array}{l}\text { Elevada actividad antioxidante, protege } \\
\text { contra el daño oxidativo por diversos } \\
\text { mecanismos: eliminación del oxígeno } \\
\text { singlete; capta radicales para prevenir } \\
\text { reacciones en cadena; preservación } \\
\text { de la estructura de la membrana } \\
\text { mediante la inhibición de la peroxidación } \\
\text { lipídica; mejora de la función del } \\
\text { sistema inmunitario y la regulación de } \\
\text { la expresión génica } \\
\text { Mecanismo de respuesta al estrés } \\
\text { oxidativo }\end{array}$ & $\begin{array}{l}\text { Antioxidantes, proteger } \\
\text { de los rayos UV, biodis- } \\
\text { ponibilidad, colorante } \\
\text { alimentario, alimentación } \\
\text { animal, mejorar las } \\
\text { funciones inmunes, } \\
\text { mejorar la salud de los } \\
\text { ojos / piel, propiedad } \\
\text { antienvejecimiento, far- } \\
\text { macéutico, nutracéutico, } \\
\text { cosmecéutico, acuacultura. }\end{array}$ & (Shah et al., 2016) \\
\hline $\begin{array}{l}13-0-(\beta \text {-galactosyl })- \\
\text { porphyra-334 }\end{array}$ & $\begin{array}{l}\text { Aminoácido } \\
\text { micosporina } \\
\text { glicosilada }\end{array}$ & $\begin{array}{l}\text { Mónera; Cyanobacteria; } \\
\text { Nostoc sphaericum }\end{array}$ & $\begin{array}{l}\text { Eliminación de radicales libres y } \\
\text { actividad de protección UV }\end{array}$ & $\begin{array}{l}\text { Sustancia nueva (se evaluó } \\
\text { resistencia a radiación } \\
\text { UV, toxicidad y actividad } \\
\text { antioxidante) }\end{array}$ & $\begin{array}{l}\text { (Ishihara et al., } \\
\text { 2017) }\end{array}$ \\
\hline Ácido gálico & \multirow{3}{*}{$\begin{array}{l}\text { Compuestos } \\
\text { fenólicos }\end{array}$} & $\begin{array}{l}\text { Protista; Euglenozoa: } \\
\text { Euglena cantábrica } \\
\text { Protista; Chlorophyta; } \\
\text { Ankistrodesmus sp. }\end{array}$ & $\begin{array}{l}\text { Mecanismos de defensa contra altos } \\
\text { niveles de ROS }\end{array}$ & $\begin{array}{l}\text { Usado para tratar enferme- } \\
\text { dades cardiovasculares, } \\
\text { quimioprevención } \\
\text { de cánceres y daños } \\
\text { mitocondriales de varios } \\
\text { tejidos. }\end{array}$ & $\begin{array}{l}\text { (Jerez-Martel et al., } \\
2017\end{array}$ \\
\hline $\begin{array}{l}\text { Ácido protocate- } \\
\text { cuico } \\
\text { Catequina } \\
\text { Ácido clorogénico }\end{array}$ & & \multirow[t]{2}{*}{$\begin{array}{l}\text { Protista; Euglenozoa; } \\
\text { Euglena cantábrica y } \\
\text { Protista; Chlorophyta; } \\
\text { Ankistrodesmus sp. }\end{array}$} & $\begin{array}{l}\text { Participa en mecanismos de defensa de } \\
\text { micro algas contra altos niveles de ROS }\end{array}$ & $\begin{array}{l}\text { Utilizados en la industria } \\
\text { farmacéutica. }\end{array}$ & $\begin{array}{l}\text { (Jerez-Martel et al., } \\
\text { 2017) }\end{array}$ \\
\hline Resveratrol & & & $\begin{array}{l}\text { Antioxidante (inhibición de la formación } \\
\text { de } 8-\mathrm{OH}-\mathrm{dG} \text { en el ADN) Efecto preventivo } \\
\text { sobre la peroxidación lipídica }\end{array}$ & $\begin{array}{l}\text { Industrias farmacéuticas, } \\
\text { alimentarias y cosméticas, } \\
\text { suplemento nutricional; } \\
\text { se incluye en algunos } \\
\text { productos cosméticos, } \\
\text { bebidas energéticas y otros } \\
\text { productos }\end{array}$ & (Li et al., 2015) \\
\hline Ficocianina & $\begin{array}{l}\text { Pigmento } \\
\text { proteínico }\end{array}$ & $\begin{array}{l}\text { Mónera; Cyanobacteria; } \\
\text { Spirulina platensis, y } \\
\text { Mónera; Cyanobacteria; } \\
\text { Spirulina maxima }\end{array}$ & $\begin{array}{l}\text { Disminución de los radicales de peroxilo, } \\
\text { peroxidación lipídica, colesterol total } \\
\text { (CHOL), lipoproteínas de baja densidad } \\
\text { (LDL), COX-2, iNOS, ROS, MDA, TNF-o, } \\
\text { IL-6 e IL-1 }\end{array}$ & $\begin{array}{l}\text { Industria farmacéutica } \\
\text { (antioxidantes, antiinfla- } \\
\text { matorios, anticancerígenos, } \\
\text { antivirales y antibacte- } \\
\text { rianos, efectos positivos } \\
\text { contra la hiperlipidemia, } \\
\text { desnutrición, obesidad, } \\
\text { diabetes, toxicidad } \\
\text { inducida por productos } \\
\text { químicos de metales } \\
\text { pesados y anemia) }\end{array}$ & (Wu et al., 2016) \\
\hline
\end{tabular}




\begin{tabular}{l|l|l|l|l}
\hline $\begin{array}{l}\text { Polisacáridos } \\
\text { sulfatados }\end{array}$ & Polisacáridos & $\begin{array}{l}\text { Repara daños del ADN, protección } \\
\text { contra lesiones hipoxias, disminución del } \\
\text { estrés oxidativo, captura superóxidos e } \\
\text { hidroxilos, inhibición de la peroxidación } \\
\text { lipídica } \\
\text { Disminuye el contenido antioxidante de } \\
\text { las células, induce de la apoptosis de } \\
\text { células tumorales } \\
\text { Inhibición de la actividad de la } \\
\text { polimerasa del ADN, disminución de } \\
\text { la demanda de fósforo, inhibición de la } \\
\text { producción de aniones de superóxido }\end{array}$ & (Wu et al., 2016) \\
Ácido $\gamma$ - linolénico & Ácido graso & & \\
\hline
\end{tabular}


fotoinducido, envejecimiento de la piel y cáncer de piel (radiación UB-B) o daños en la estructura del colágeno (radiación UV-A), por lo que incluir moléculas capaces de absorber esta radiación mejora la eficiencia en la protección de la piel humana (Hüglin, 2016).

\section{Mecanismo de acción de antioxidantes en la piel y cabello}

Las ROS son capaces de causar graves daños en los organismos vivos. Pueden originarse debido a procesos de óxido-reducción internos, metabolismo aerobio y daño oxidativo o por factores externos, como la radiación UV y la contaminación ambiental (humo de tabaco, pesticidas, etc.) (Berthon et al., 2017). De acuerdo con Nowruzi et al. (2020), la piel y el cabello son las partes del cuerpo más expuestas a estos factores generadores de ROS, por lo que el uso de antioxidantes naturales en la industria cosmética representa la mejor solución para contrarrestar el daño oxidativo ocasionado por factores externos o endógenos.

La piel tiene su propio sistema para combatir los RLs y reducir su impacto en las células. El sistema antioxidante de la piel está integrado principalmente por antioxidantes enzimáticos como: sintasa de $\mathrm{O}_{2}$, superóxido dismutasa citosólica y mitocondrial, glutatión peroxidasa, catalasa y ciertas vitaminas, entre otros (Hüglin, 2016). Además, tanto la piel como el cabello producen un tipo de melanina para protegerse del daño oxidativo, la eumelanina, que reduce la acumulación de fotoproductos inducidos por la luz UV (Palareti et al., 2016).

En las últimas décadas el desarrollo de las industrias de siderúrgica, minera, textil y agropecuaria ha provocado un gran impacto ambiental ( $\mathrm{Li}$ et al., 2020), lo que ha incrementado la contaminación y la radiación UV por disminución de la capa de ozono (Malanca y Arguello, 2017). Por ello, el desarrollo de productos con compuestos antioxidantes y absorbentes de luz UV para la protección de la piel es altamente demandado gracias a la capacidad de estos compuestos de neutralizar radicales de oxígeno y peróxidos para ayudar a reducir los daños causados por estrés oxidativo y por la radiación en el ADN celular (figura 1) (Hüglin, 2016).

\section{Ensayos de verificación de la actividad antioxi- dante de compuestos naturales}

La capacidad antioxidante se puede medir mediante ensayos in vitro. Estos ensayos se clasifican en aquellos basados en la transferencia de átomos de hidrógeno (HAT) para medir la habilidad de captar radicales de hidrógeno o los basados en la transferencia de electrones (ET) (Camarena-Tello et al., 2018). A continuación, se describe el fundamento de los ensayos más comúnmente utilizados:

\section{Ensayo DPPH (2,20-difenil-1-picrylhydrazyl radical)}

Este ensayo es el más utilizado para la determinación de la actividad antioxidante de extractos obtenidos de microorganismos (Badr et al., 2019). El radical DPPH tiene coloración violeta y cuando se coloca delante de una molécula capaz de reducirla a hidrazina hay un cambio en su coloración a amarillo pálido (Pedroso et al., 2019). La reducción ocurre debido a la transferencia de un átomo de hidrógeno, por lo que es un ensayo tipo HAT. Las moléculas capaces de reducir el DPPH son los agentes antioxidantes probados. El radical violeta DPPH remanente se mide con un espectrofotómetro UV-Vis a aproximadamente 515$520 \mathrm{~nm}$ y así se determina la actividad antioxidante del compuesto (Sirivibulkovit et al., 2018).

\section{Ensayo ORAC (capacidad de absorción de radicales de oxígeno)}

La capacidad de absorción de radicales de oxígeno (ORAC) se clasifica como ensayo de tipo HAT (Camarena-Tello et al., 2018). En el ensayo ORAC se utiliza una sonda sintética no proteínica, la fluoresceína (FL) como sustrato oxidable y da la generación de radicales peroxilo $\left(\mathrm{RO}_{2}\right)$ mediada por dihidrocloruro de 2,2'-azobis (2-amidinopropano) (AAPH) (Amarowicz y Pegg, 2019). Los antioxidantes protegen o evitan que la fluoresceína pierda fluorescencia, ya que los $\mathrm{ROO}_{2}$ captan preferiblemente un átomo de hidrógeno del antioxidante y esta capacidad de protección se mide con un fluorómetro (Agrawal et al., 2020). En este ensayo, como agentes generadores de radicales peroxilo se puede utilizar otras sustancias como el AIBN lipó- 


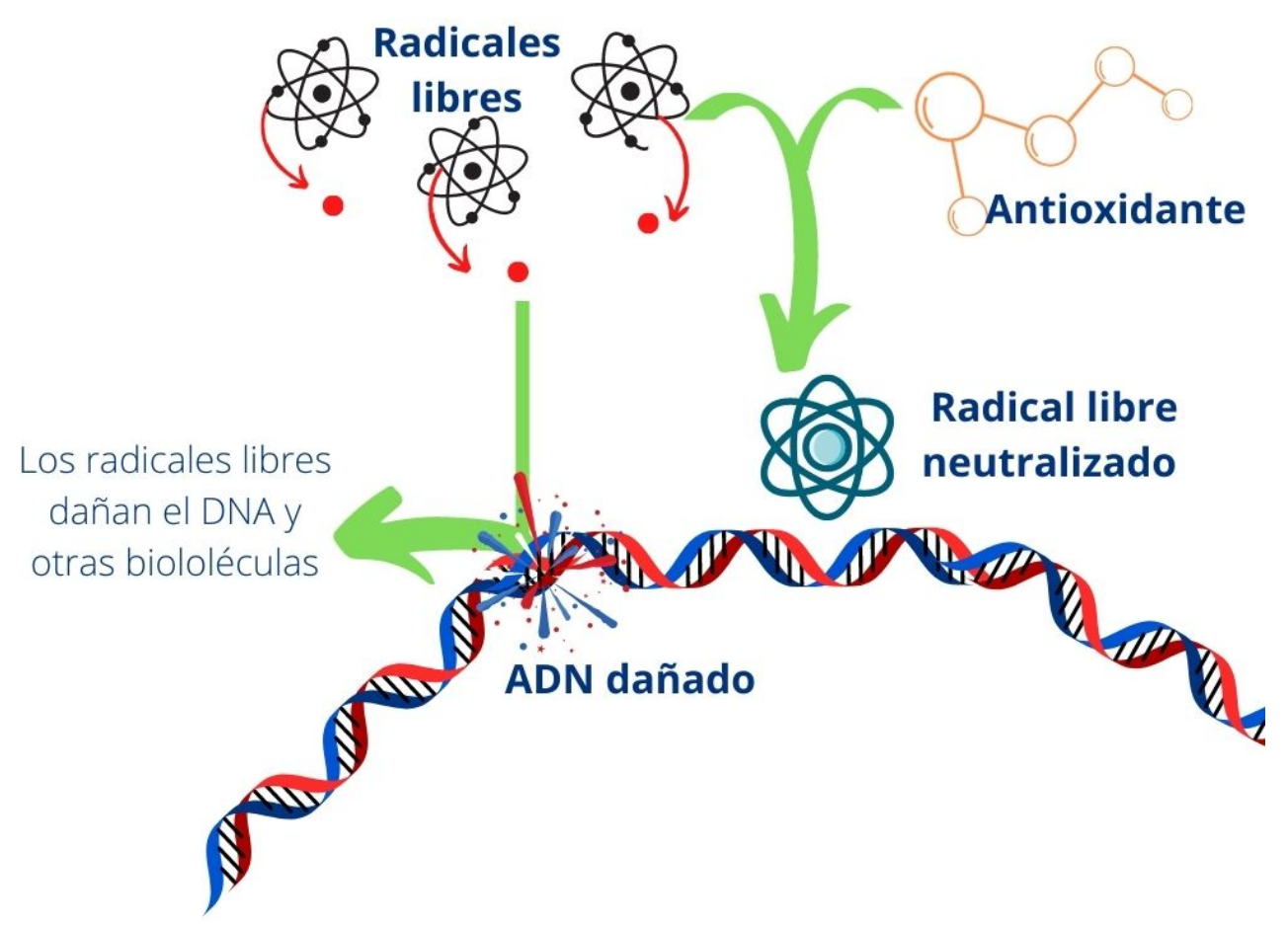

Figura 1. Los átomos de los radicales libres representan las moléculas que causan el daño oxidativo en el $A D N$ al tener un electrón de valencia no pareado. La molécula antioxidante representa el componente encargado de neutralizar los átomos de radicales libres.

filo ( $\alpha, \alpha$-azobisisobutironitrilo) que es un compuesto orgánico natural, o el ABAP (2,2-azobis (2-amidinopropano) diclorhidrato) y AMVN (2,2'azobis (2, 4-dimetilvaleronitrilo)), que son compuestos químicos sintéticos (Dorta et al., 2016).

\section{Ensayo de quimioluminiscencia por fotosensibilización $(P C L)$}

El ensayo PCL se clasifica como ensayo de tipo HAT, y se realiza en presencia de un superóxido aniónradical (Camarena-Tello et al., 2018). Se generan radicales aniones de superóxido bajo la influencia de la luz UV y un fotosensibilizador; durante la reacción se da la detección, con un compuesto quimioluminógeno (luminol). La medida de la cantidad de radicales en el sistema será la intensidad de la luz emitida y los compuestos de captura de radicales atenuarán esta intensidad de fotoquimioluminiscencia en función de la cantidad y actividad del antioxidante probado (Gramza-Michalowska et al., 2015).

\section{Ensayo FRAP (reducción férrica poder antioxidante)}

El método FRAP determina la capacidad antioxidante del compuesto basado en la reducción del complejo $\mathrm{Fe}^{3+}$-TPTZ al complejo azul $\mathrm{Fe}^{2+}$-TPTZ mediante una sustancia donadora de electrones en condición ácida (Ceylan et al., 2019), por lo que es un ensayo ET. El cambio de color se puede correlacionar con la capacidad antioxidante al medir la absorbancia a $450 \mathrm{~nm}$ (Oniga et al., 2018).

Los ensayos de evaluación de la actividad antioxidante in vitro detallados previamente son ampliamente utilizados y presentan ventajas como la sencillez, precisión, asequibilidad y relativa rapidez de desarrollo. Además, ensayos como el DPPH permiten controlar la evolución temporal de la reacción, por lo que proporcionan datos valiosos. Sin embargo, son utilizados para detecciones preliminares, dado que no proporcionan información de la actividad biológica de los antioxidantes que brindan solamente 
las pruebas in vivo, pero estas implican altos costos y pueden plantear problemas éticos; por esto se pueden usar como sustitutos los ensayos en líneas celulares representativas, para lo cual se somete el cultivo celular a alguna fuente de estrés oxidativo en presencia o ausencia del antioxidante y se evalúa el daño en células tratadas versus células no tratadas (Amorati y Valgimigli, 2015).

\section{Procesos de evaluación de compuestos antioxi- dantes para usar cosméticos}

De acuerdo con Millington y Marsh, (2020), el uso de aditivos naturales, no tóxicos en productos cosméticos, es un proceso mucho más atractivo que el utilizar aditivos sintéticos. Para utilizar productos naturales de interés en cosméticos se debe evaluar su toxicidad, citotoxicidad, fototoxicidad, carcinogenicidad y efectos mutagénicos (Nowruzi et al., 2020), para lo cual se pueden utilizar células o tejidos humanos, al igual que animales de laboratorio como los ratones (Tuttle et al., 2018).

\section{Ensayos de toxicidad en animales}

Una vez pasadas las pruebas de fototoxicidad se utilizan ratones outbred, ya que al igual que los humanos, cada ratón de este tipo es diferente a otro, por lo que cada uno reaccionará de manera distinta al producto (Suh et al., 2018).

Se puede tratar a los animales primero con el producto químico con una dosis de $2000 \mathrm{mg} / \mathrm{kg}$ y se determina la morbilidad y mortalidad relacionadas con el compuesto. Si ninguno de los animales muere, se suspenden las siguientes pruebas de toxicidad. Si algunos mueren, se realizan pruebas de toxicidad a dosis menores entre 200 y $20 \mathrm{mg} / \mathrm{kg}$. Se puede considerar un índice de toxicidad aguda de aproximadamente $4000 \mathrm{mg} / \mathrm{kg}$ o más cuando no hay mortalidad a la dosis de $2000 \mathrm{mg} / \mathrm{kg}$ (Mishra et al., 2018).

\section{Ensayos de toxicidad en líneas celulares mamíferas}

Los animales de laboratorio representan un costo elevado y no brindan resultados de alto rendimiento, por lo que las células mamíferas obtenidas de diferentes tejidos son una mejor alternativa (Huang et al., 2016). Para ensayos toxicológicos se utilizan, por lo general, células del tejido epitelial como los fibroblastos, ya que brindan resultados más exactos de toxicidad para humanos y no exigen condiciones complejas de crecimiento; se las puede mantener en medio DMEM (Dulbeco's Modified Eagle's Medium) a $37^{\circ} \mathrm{C}$ en una atmósfera húmeda con $5 \%$ de $\mathrm{CO}_{2}$ (Huang et al., 2016). Además, para evaluar cosméticos destinados a la cavidad bucal u otros que presenten el riesgo de ingresar a la misma, se pueden utilizar fibroblastos gingivales, los cuales pueden cultivarse también en el medio DMEM a $37^{\circ} \mathrm{C}$ en una atmósfera húmeda con $5 \%$ de $\mathrm{CO}_{2}$ (Costa et al., 2019).

\section{Ensayos de fototoxicidad y citotoxicidad}

Los ensayos de fototoxicidad evalúan la respuesta fotoinducida cuando una sustancia fotoreactiva es activada por la luz solar produciendo químicos excitados que pueden transferir la energía adsorbida y generar especies reactivas que podrían causar irritación sobre la piel (Reis-Mansur et al., 2019). Se pueden realizar disolviendo la sustancia evaluada en un buffer de fosfato de sodio, analizando el espectro de absorción UV/VIS con un espectrofotómetro y evaluando las especies reactivas de oxígeno formadas (Lee et al., 2017).

Los ensayos de citotoxicidad evalúan la capacidad de un compuesto de ocasionar daño celular. Los efectos citotóxicos se pueden determinar tratando todas las líneas celulares con las mismas dosis durante $48 \mathrm{~h}$, para poder investigar los efectos sinérgicos o antagonistas de los compuestos ensayados (Sevimli-Gur y Yesil-Celiktas, 2019).

\section{Incorporación de antioxidantes en cosméticos}

Para incorporar compuestos antioxidantes producidos por microorganismos en cosméticos se inicia con la extracción de estos para luego adicionarlos en la fase oleaginosa de la formulación cosmética (Bianchet et al., 2020). Primero se liberan las sustancias intracelulares mediante métodos físicos, químicos o biológicos y posteriormente, se separan de los desechos celulares (Mussagy et al., 2019). Después se realiza la extracción, que puede utilizar el método Soxhlet, extracción con solventes orgánicos, extracción con maceración, extracción de fluidos supercríticos y subcríticos, extracción asistida por ultraso- 
nido, extracción de líquido presurizado y extracción asistida por enzimas, entre otros, dependiendo de la sustancia que se va a obtener (Saini y Keum, 2018).

Los cosméticos pueden ser una emulsión de aceite en agua o agua en aceite. Por lo general, consisten en emolientes y lubricantes dispersos en una fase de aceite y una fase de agua que contiene agentes emulsionantes y espesantes, perfume, color y conservantes (Sugibayashi et al., 2019). Los compuestos antioxidantes se solubilizan, disuelven o dispersan en la fase de lípidos, o pueden ser incluidos en microcápsulas o liposomas, en dependencia del producto en desarrollo. Posteriormente, se puede optar por la aplicación de diferentes técnicas para homogenizar la emulsión (Yukuyama et al., 2016).

Para homogeneizar la emulsión se puede utilizar el método de alta presión para nanoemulsiones usado en cosméticos, donde la mezcla se dispersa en una solución de surfactante caliente por encima del punto de fusión por agitación a alta velocidad para obtener una pre-emulsión. Luego, la pre-emulsión pasa a través de un homogeneizador de alta presión a altas temperaturas o a temperatura ambiente, dependiendo del método, para obtener la emulsión final (Yukuyama et al., 2016).

\section{CONCLUSIONES}

Los microorganismos son fuentes de recursos naturales con gran potencial industrial. Estos recursos han atraído la atención de la industria cosmética para ser utilizados como coadyuvantes con propiedades antioxidantes, es decir, como sustancias capaces de absorber y minimizar los efectos de ROS. La fuente principal de obtención de antioxidantes son las plantas, sin embargo, sus células vegetales pueden presentar desventajas respecto al costo de mantenimiento, biosíntesis limitada de antioxidantes a ciertas zonas o dependencia de interacciones con microorganismos, entre otras.

Por lo anterior, se ha detallado una lista de diferentes tipos de microorganismos que pueden ser fuente de estos compuestos para aplicarlos, no solo en la industria cosmética, sino también en fármacos, suplementos alimenticios, nutraceúticos y en terapias médicas.
Existen varias metodologías para evaluar la actividad antioxidante de diferentes tipos de sustancias como el ensayo DPPH, ORAIC o PCL; pero estas pruebas son solo el inicio para poder emplearlas en cosméticos, ya que estos, al ser aplicados directamente sobre células humanas deben pasar por ensayos toxicológicos en líneas celulares de mamíferos o directamente en animales de laboratorio, y así formar parte de la fase lipídica de los cosméticos.

Con esta evidencia sobre la actividad antioxidante de varios compuestos obtenidos de microorganismos acuáticos y terrestres, a futuro, es necesaria la elaboración de estudios sobre la actividad antioxidante de compuestos obtenidos de especies de microorganismos endémicos de diferentes zonas para aprovechar su accesibilidad y potencial en diversas aplicaciones de interés humano; así como de investigaciones sobre la estabilización de estos compuestos, formulación viable para su mantenimiento y la concentración necesaria para desencadenar la actividad biológica esperada.

\section{AGRADECIMIENTOS}

Esta revisión fue realizada con el apoyo de la Universidad Técnica de Ambato, que facilitó el acceso a las diferentes bases de datos utilizadas.

\section{CONFLICTO DE INTERESES}

La autora declara no tener conflicto de intereses.

\section{REFERENCIAS}

Agrawal, S., Deshmukh, S. K., Reddy, M. S., Prasad, R., \& Goel, M. (2020). Endolichenic fungi: A hidden source of bioactive metabolites. South African Journal of Botany, 000, 1-24 (2019). DOI:10.1016/j.sajb.2019.12.008

Amarowicz, R., \& Pegg, R. B. (2019). Natural antioxidants of plant origin. Advances in Food and Nutrition Research, 90(1), 1-81. DOI:10.1016/bs.afnr.2019.02.011

Ambati, R. R., Gogisetty, D., Aswathanarayana, R. G., Ravi, S., Bikkina, P. N., Bo, L., \& Yuepeng, S. (2019). Industrial potential of carotenoid pigments from microalgae: Current trends and future prospects. Critical Reviews in Food Science and Nutrition, 59(12), 1880-1902. DOI:10.1080/10408398.2018.1432561

Amorati, R., \& Valgimigli, L. (2015). Advantages and 
limitations of common testing methods for antioxidants. Free Radical Research, 49(5), 633-649. DOI:10.3109/10715762.2014.996146

Atanasov, A. G., Waltenberger, B., Pferschy-Wenzig, E. M., Linder, T., Wawrosch, C., Uhrin, P., Temml, V., Wang, L., Schwaiger, S., Heiss, E. H., Rollinger, J. M., Schuster, D., Breuss, J. M., Bochkov, V., Mihovilovic, M. D., Kopp, B., Bauer, R., Dirsch, V. M., \& Stuppner, H. (2015). Discovery and resupply of pharmacologically active plant-derived natural products: A review. Biotechnology Advances, 33(8), 1582-1614. DOI:10.1016/j.biotechadv.2015.08.001

Badr, O. A. M., EL-Shawaf, I. I. S., El-Garhy, H. A. S., Moustafa, M. M. A., \& Ahmed-Farid, O. A. (2019). The potent therapeutic effect of novel cyanobacterial isolates against oxidative stress damage in redox rats. Journal of Applied Microbiology, 126(4), 1278-1289. DOI:10.1111/jam.14200

Baker, B. J., Appler, K. E., \& Gong, X. (2020). New microbial biodiversity in marine sediments. Annual Review of Marine Science, 13(1). 161-175. DOI:10.1146/annurevmarine-032020-014552

Bazinet, L., \& Doyen, A. (2015). Antioxidants, mechanisms, and recovery by membrane processes. Critical Reviews in Food Science and Nutrition, 57(4), 677-700. DOI:10.1080/10408398.2014.912609

Berthon, J. Y., Nachat-Kappes, R., Bey, M., Cadoret, J. P., Renimel, I., \& Filaire, E. (2017). Marine algae as attractive source to skin care. Free Radical Research, 51(6), DOI:10.1080/10715762.2017.1355550

Bianchet, R. T., Vieira Cubas, A. L., Machado, M. M., \& Siegel Moecke, E. H. (2020). Applicability of bacterial cellulose in cosmetics - bibliometric review. Biotechnology Reports, 27, 1-6. DOI:10.1016/j.btre.2020.e00502

Bouiche, C., Boucherba, N., Benallaoua, S., Martinez, J., Diaz, P., Pastor, F. I. J., \& Valenzuela, S. V. (2020). Differential antioxidant activity of glucuronoxylooligosaccharides (UXOS) and arabinoxylooligosaccharides (AXOS) produced by two novel xylanases. International Journal of Biological Macromolecules, 155, 1075-1083. DOI:10.1016/j.ijbiomac.2019.11.073

Camarena-Tello, J. C., Martínez-Flores, H. E., GarnicaRomo, M. G., Padilla-Ramírez, J. S., Saavedra-Molina, A., Alvarez-Cortes, O., Bartolomé-Camacho, M. C., \& Rodiles-López, J. O. (2018). Quantification of phenolic compounds and in vitro radical scavenging abilities with leaf extracts from two varieties of Psidium guajava L. Antioxidants, 7(3), 1-12. DOI:10.3390/antiox7030034

Ceylan, S., Cetin, S., Camadan, Y., Saral, O., Ozsen, O., \& Tutus, A. (2019). Antibacterial and antioxidant activities of traditional medicinal plants from the Erzurum region of Turkey. Irish Journal of Medical Science, 188(4), 13031309. DOI:10.1007/s11845-019-01993-x

Chandra, P., Sharma, R. K., \& Arora, D. S. (2020). Antioxidant compounds from microbial sources: A review. Food Research International, 129, 1088-1149. DOI:10.1016/j.foodres.2019.108849

Cheng, Y. T., \& Yang, C. F. (2016). Using strain Rhodotorula mucilaginosa to produce carotenoids using food wastes. Journal of the Taiwan Institute of Chemical Engineers,
61, 270-275. DOI:10.1016/j.jtice.2015.12.027

Costa, C. R. R., Amorim, B. R., da Silva, S. M. M., Acevedo, A. C., Magalhães, P. D. O., \& Guerra, E. N. S. (2019). In vitro evaluation of Eugenia dysenterica in primary culture of human gingival fibroblast cells. Brazilian Oral Research, 33, e035. DOI:10.1590/1807-3107BOR2019.VOL33.0035

Cottrez, F., Boitel, E., Berrada-Gomez, M. P., Dalhuchyts, H., Bidan, C., Rattier, S., Ferret, P. J., \& Groux, H. (2020). In vitro measurement of skin sensitization hazard of mixtures and finished products: Results obtained with the SENS-IS assays. Toxicology In vitro, 62, 104644. DOI:10.1016/j.tiv.2019.104644

Danagoudar, A., Joshi, C. G., Sunil Kumar, R., Poyya, J., Nivya, T., Hulikere, M. M., \& Anu Appaiah, K. (2017). Molecular profiling and antioxidant as well as antibacterial potential of polyphenol producing endophytic fungus-Aspergillus austroafricanus CGJ-B3. Mycology, 8(1), 28-38. DOI:10.1080/21501203.2017.1281358

De la Vega, M., Sayago, A., Ariza, J., Barneto, A. G., \& León, R. (2016). Characterization of a bacterioruberinproducing Haloarchaea isolated from the marshlands of the Odiel river in the southwest of Spain. Biotechnology Progress, 32(3), 592-600. DOI:10.1002/btpr.2248

Dorta, E., Rodríguez-Rodríguez, E. M., Jiménez-Quezada, A., Fuentes-Lemus, E., Speisky, H., Lissi, E., \& LópezAlarcón, C. (2016). Use of the oxygen radical absorbance capacity (ORAC) assay to predict the capacity of Mango (Mangifera indica L.) by-products to inhibit meat protein oxidation. Food Analytical Methods, 10(2), 330-338. DOI:10.1007/S12161-016-0584-5

Dwibedi, V., \& Saxena, S. (2018). Arcopilus aureus, a resveratrol-producing endophyte from Vitis vinifera. Applied Biochemistry and Biotechnology, 186(2), 476-495. DOI:10.1007/s12010-018-2755-x

Dwibedi, V., \& Saxena, S. (2020). In vitro anti-oxidant, antifungal and anti-staphylococcal activity of resveratrolproducing endophytic fungi. Proceedings of the National Academy of Sciences India Section B - Biological Sciences, 90 (1), 207-219. DOI:10.1007/s40011-019-01098-6

Fagundes, M. B., Falk, R. B., Facchi, M. M. X., Vendruscolo, R. G., Maroneze, M. M., Zepka, L. Q., JacobLopes, E., \& Wagner, R. (2019). Insights in cyanobacteria lipidomics: A sterols characterization from Phormidium autumnale biomass in heterotrophic cultivation. Food Research International, 119, 777-784. DOI:10.1016/j.foodres.2018.10.060

Gramza-Michalowska, A., Sidor, A., Regula, J., \& Kulczynski, B. (2015). PCL assay application in superoxide anion-radical scavenging capacity of tea Camellia sinensis extracts. Acta Scientiarum Polonorum, Technologia Alimentaria, 14(4), 331-341. DOI:10.17306/J.AFS.2015.4.33

Hamed, I. (2016). The evolution and versatility of microalgal biotechnology: A review. Comprehensive Reviews in Food Science and Food Safety, 15(6), 1104-1123. DOI:10.1111/1541-4337.12227

Hamidi, M., Safarzadeh Kozani, P., Safarzadeh Kozani, P., Pierre, G., Michaud, P., \& Delattre, C. (2020). Marine bacteria versus microalgae: Who is the best for bio- 
technological production of bioactive compounds with antioxidant properties and other biological applications? Marine Drugs, 18(1), 28-46. DOI:10.3390/md18010028

Hęś, M., Dziedzic, K., Górecka, D., Jędrusek-Golińska, A., \& Gujska, E. (2019). Aloe vera (L.) Webb.: Natural sources of antioxidants - A review. Plant Foods for Human Nutrition, 74 (3), 255-265. DOI:10.1007/s11130-019-00747-5

Hidalgo, D., Sanchez, R., Lalaleo, L., Bonfill, M., Corchete, P., \& Palazon, J. (2018). Biotechnological production of pharmaceuticals and biopharmaceuticals in plant cell and organ cultures. Current Medicinal Chemistry, 25(30), 3577-3596. DOI:10.2174/0929867325666180309124317

Hou, J., \& Cui, H. L. (2018). In vitro antioxidant, antihemolytic, and anticancer activity of the carotenoids from halophilic archaea. Current Microbiology, 75 (3), 266-271. DOI:10.1007/s00284-017-1374-z

Huang, C., Zhang, Z., \& Cui, W. (2019). Marinederived natural compounds for the treatment of Parkinson's disease. Marine Drugs, 17(4), 221-240. DOI:10.3390/md17040221

Huang, R., Xia, M., Sakamuru, S., Zhao, J., Shahane, S. A., Attene-Ramos, M., Zhao, T., Austin, C. P., \& Simeonov, A. (2016). Modelling the Tox21 $10 \mathrm{~K}$ chemical profiles for in vivo toxicity prediction and mechanism characterization. Nature Communications, 7, 1-10. DOI:10.1038/ncomms10425

Hüglin, D. (2016). Advanced UV absorbers for the protection of human skin. Chimia, $70(7-8)$, 496-501. DOI:10.2533/chimia.2016.496

Ishihara, K., Watanabe, R., Uchida, H., Suzuki, T., Yamashita, M., Takenaka, H., Nazifi, E., Matsugo, S., Yamaba, M., \& Sakamoto, T. (2017). Novel glycosylated mycosporinelike amino acid, 13-O-( $\beta$-galactosyl)-porphyra-334, from the edible cyanobacterium Nostoc sphaericum-protective activity on human keratinocytes from UV light. Journal of Photochemistry and Photobiology B: Biology, 172, 102108. DOI:10.1016/j.jphotobiol.2017.05.019

Jerez-Martel, I., García-Poza, S., Rodríguez-Martel, G., Rico, M., Afonso-Olivares, C., \& Gómez-Pinchetti, J. L. (2017). Phenolic profile and antioxidant activity of crude extracts from microalgae and cyanobacteria strains. Journal of Food Quality, 2017, 2924508. DOI:10.1155/2017/2924508 bibitemKaboré, A. K., Olmos, E., Fick, M., Blanchard, F., Guedon, E., \& Delaunay, S. (2017). Aerobiosis-anaerobiosis transition has a significant impact on organic acid production by Corynebacterium glutamicum. Process Biochemistry, 52, 10-21. DOI:10.1016/j.procbio.2016.10.007

Khan, I., \& Ahmad, A. (2020). The impact of natural antioxidants on human health. In S. Ahmad, \& N. A. AlShabib (Eds.), Functional Food Products and Sustainable Health (pp.11-24). Springer Singapore. DOI:10.1007/978981-15-4716-4_2

Kot, A. M., Błazejak, S., Gientka, I., Kieliszek, M., \& Bryś, J. (2018). Torulene and torularhodin: "New" fungal carotenoids for industry? Microbial Cell Factories, 17, 49-63. DOI:10.1186/s12934-018-0893-z

Lee, Y. S., Yi, J. S., Lim, H. R., Kim, T. S., Ahn, I. Y., Ko, K., Kim, J. H., Park, H. K., Sohn, S. J., \& Lee, J. K. (2017). Phototoxicity evaluation of pharmaceu- tical substances with a reactive oxygen species assay using ultraviolet a. Toxicological Research, 33(1), 43-48. DOI:10.5487/TR.2017.33.1.043

Li, B., Zhou, Z., Xue, Z., Wei, P., Ren, Y., Cao, L., Feng, X., Yao, Q., Ma, J., Xu, P., \& Chen, X. (2020). Study on the pollution characteristics and sources of ozone in typical loess Plateau City. Atmosphere, 11(6). DOI:10.3390/atmos11060555

Li, M., Kildegaard, K. R., Chen, Y., Rodriguez, A., Borodina, I., \& Nielsen, J. (2015). De novo production of resveratrol from glucose or ethanol by engineered $S a c$ charomyces cerevisiae. Metabolic Engineering, 32, 1-11. DOI:10.1016/j.ymben.2015.08.007

Liu, J., Mao, X., Zhou, W., \& Guarnieri, M. T. (2016). Simultaneous production of triacylglycerol and high-value carotenoids by the astaxanthin-producing oleaginous green microalga Chlorella zofingiensis. Bioresource Technology, 214, 319-327. DOI:10.1016/j.biortech.2016.04.112

Lutzu, G. A., \& Dunford, N. T. (2018). Interactions of microalgae and other microorganisms for enhanced production of high-value compounds. Frontiers in Bioscience - Landmark, 23(8), 1487-1504. DOI:10.2741/4656

Malanca, F., \& Arguello, G. (2017). Cuando hacemos las cosas mal. La disminución de la capa de ozono y el cambio climático, dos problemas ambientales a escala global. Bitácora Digital, 4 (8), 1-4. DOI:11336/121482

Mendes-Silva, T. de C. D., Andrade, R. F. da S., Ootani, M. A., Mendes, P. V. D., Sá, R. A. de Q. C. de, Silva, M. R. F. da, Souza, K. S., Correia, M. T. dos S., Silva, M. V. da, \& Oliveira, M. B. M. de. (2020). Biotechnological potential of carotenoids produced by extremophilic microorganisms and application prospects for the cosmetics industry. Advances in Microbiology, 10 (08), 397-410. DOI:10.4236/aim.2020.108029

Millington, K. R., \& Marsh, M. (2020). UV damage to hair and the effect of antioxidants and metal chelators. International Journal of Cosmetic Science, 42, 174-184. DOI:10.1111/ics.12601

Mishra, A. K., Mishra, A., Pragya, \& Chattopadhyay, P. (2018). Screening of acute and sub-chronic dermal toxicity of Calendula officinalis $\mathrm{L}$ essential oil. Regulatory Toxicology and Pharmacology, 98, 184-189. DOI:10.1016/j.yrtph.2018.07.027

Mussagy, C. U., Winterburn, J., Santos-Ebinuma, V. C., \& Pereira, J. F. B. (2019). Production and extraction of carotenoids produced by microorganisms. Applied Microbiology and Biotechnology, 103(3), 1095-1114. DOI:10.1007/s00253-018-9557-5

Ndongo, S., Khelaifia, S., Lagier, J. C., \& Raoult, D. (2020). From anaerobes to aerointolerant prokaryotes. Human Microbiome Journal, 15, 100068. DOI:10.1016/j.humic.2019.100068

Neha, K., Haider, M. R., Pathak, A., \& Yar, M. S. (2019). Medicinal prospects of antioxidants: A review. European Journal of Medicinal Chemistry, 178, 687-704. DOI:10.1016/j.ejmech.2019.06.010

Novoveská, L., Ross, M. E., Stanley, M. S., Pradelles, R., Wasiolek, V., \& Sassi, J. F. (2019). Microalgal carotenoids: A review of production, current markets, regulations, and future direction. Marine Drugs, 17(11), 1-21. 
DOI: $10.3390 / \mathrm{md} 17110640$

Nowruzi, B., Sarvari, G., \& Blanco, S. (2020). The cosmetic application of cyanobacterial secondary metabolites. Algal Research, 49, 101959. DOI:10.1016/j.algal.2020.101959

Oniga, I., Pus, C., Silaghi-Dumitrescu, R., Olah, N. K., Sevastre, B., Marica, R., Marcus, I., Sevastre-Berghian, A. C., Benedec, D., Pop, C. E., \& Hanganu, D. (2018). Origanum vulgare ssp. vulgare: Chemical composition and biological studies. Molecules, 23(8), 2077. DOI:10.3390/molecules23082077

Palareti, G., Legnani, C., Cosmi, B., Antonucci, E., Erba, N., Poli, D., Testa, S., \& Tosetto, A. (2016). Mechanisms and prevention of UV-induced melanoma. International Journal of Laboratory Hematology, 38(1), 42-49. DOI:10.1111/ijlh.12426

Patel, A., Rova, U., Christakopoulos, P., \& Matsakas, L. (2019). Simultaneous production of DHA and squalene from Aurantiochytrium sp. grown on forest biomass hydrolysates. Biotechnology for Biofuels, 12(1), 1-12. DOI:10.1186/s13068-019-1593-6

Pedroso, S., Luíza, D., Pinheiro, N., Marques, N., Susin, B., \& Dal, V. (2019). Production of metabolites with antioxidant activity by Botryosphaeria dothidea in submerged fermentation. Bioprocess and Biosystems Engineering, 43, 13-20. DOI:10.1007/s00449-019-02200-y

Penchaszadeh, P. E. (2017). Ciencia Hoy $N^{\circ}$ 15\%. Ciencia Hoy. http://ebookcentral.proquest.com/lib/utasp/ detail.action?docID $=5349514$

Pengkumsri, N., Kaewdoo, K., Leeprechanon, W., \& Sivamaruthi, B. S. (2019). Influence of extraction methods on total phenolic content and antioxidant properties of some of the commonly used plants in Thailand. $P a$ kistan Journal of Biological Sciences, 22(3), 117-126. DOI:10.3923/pjbs.2019.117.126

Petruk, G., Roxo, M., De Lise, F., Mensitieri, F., Notomista, E., Wink, M., Izzo, V., \& Monti, D. M. (2019). The marine Gram-negative bacterium Novosphingobium sp. PP1Y as a potential source of novel metabolites with antioxidant activity. Biotechnology Letters, 41(2), 273281. DOI:10.1007/s10529-018-02636-4

Peyrat, L. A., Tsafantakis, N., Georgousaki, K., Ouazzani, J., Genilloud, O., Trougakos, I. P., \& Fokialakis, N. (2019). Terrestrial microorganisms: Cell factories of bioactive molecules with skin protecting applications. Molecules, 24(9), 1836. DOI:10.3390/molecules24091836

Prihantini, A. I., \& Tachibana, S. (2017). Antioxidant compounds produced by Pseudocercospora sp. ESL 02, an endophytic fungus isolated from Elaeocarpus sylvestris. Asian Pacific Journal of Tropical Biomedicine, 7(2), 110115. DOI:10.1016/j.apjtb.2016.11.020

Ragavan, M. L., \& Das, N. (2019). Optimization of exopolysaccharide production by probiotic yeast Lipomyces starkeyi VIT-MN03 using response surface methodology and its applications. Annals of Microbiology, 69(5), 515-530. DOI:10.1007/s13213-019-1440-9

Ramana, K. V, Reddy, A. B. M., Ravi, N. V, Majeti, K., \& Singhal, S. S. (2018). Therapeutic potential of natural antioxidants. Oxidative Medicine and Cellular Longevity, 2018, 9471051. DOI:10.1155/2018/9471051

Reis-Mansur, M. C. P. P., Cardoso-Rurr, J. S., Silva, J. V. M.
A., de Souza, G. R., Cardoso, V. da S., Mansoldo, F. R. P., Pinheiro, Y., Schultz, J., Lopez Balottin, L. B., da Silva, A. J. R., Lage, C., dos Santos, E. P., Rosado, A. S., \& Vermelho, A. B. (2019). Carotenoids from UV-resistant Antarctic Microbacterium sp. LEMMJ01. Scientific Reports, 9(1), 9554. DOI:10.1038/s41598-019-45840-6

Ribera, M. (2019). Similarities, differences and mechanisms of climate impact on terrestrial vs. Marine ecosystems. Nature Conservation, 34, 505-523. Pensoft Publishers. DOI:10.3897/natureconservation.34.30923

Rogiers, V., Benfenati, E., Bernauer, U., Bodin, L., Carmichael, P., Chaudhry, Q., Coenraads, P. J., Cronin, M. T. D., Dent, M., Dusinska, M., Ellison, C., Ezendam, J., Gaffet, E., Galli, C. L., Goebel, C., Granum, B., Hollnagel, H. M., Kern, P. S., KosemundMeynen, K., ... Worth, A. (2020). The way forward for assessing the human health safety of cosmetics in the EU - Workshop proceedings. Toxicology, 436, 152421. DOI:10.1016/j.tox.2020.152421

Saini, R. K., \& Keum, Y. S. (2018). Carotenoid extraction methods: A review of recent developments. Food Chemistry, 240, 90-103. DOI:10.1016/j.foodchem.2017.07.099

Sakthivel, R., \& Devi, K. P. (2019). Antioxidant, antiinflammatory and anticancer potential of natural bioactive compounds from seaweeds. In Studies in Natural Products Chemistry, (pp. 113-154). Elsevier Inc. DOI:10.1016/B978-0-12-817901-7.00005-8

Satoh, K., \& Oono, Y. (2019). Studies on application of ion beam breeding to industrial microorganisms at TIARA. Quantum Beam Science, 3(2), 11. DOI:10.3390/qubs3020011

Sevimli-Gur, C., \& Yesil-Celiktas, O. (2019). Cytotoxicity screening of supercritical fluid extracted seaweeds and phenylpropanoids. Molecular Biology Reports, 46(4), 3691-3699. DOI:10.1007/s11033-019-04812-9

Shah, M. M. R., Liang, Y., Cheng, J. J., \& Daroch, M. (2016). Astaxanthin-producing green microalga Haematococcus pluvialis: From single cell to high value commercial products. Frontiers in Plant Science, 7, 531. DOI:10.3389/fpls.2016.00531

Singh, Davinder Pal, Khattar, J. S., Rajput, A., Chaudhary, R., \& Singh, R. (2019). High production of carotenoids by the green microalga Asterarcys quadricellulare PUMCC 5.1.1 under optimized culture conditions. PLoS ONE, 14(9), 119. DOI:10.1371/journal.pone.0221930

Singh, Dhananjaya P, Prabha, R., Verma, S., Meena, K. K., \& Yandigeri, M. (2017). Antioxidant properties and polyphenolic content in terrestrial cyanobacteria. 3 Biotech, 7(2), 134. DOI:10.1007/s13205-017-0786-6

Sirivibulkovit, K., Nouanthavong, S., \& Sameenoi, Y. (2018). Paper-based DPPH assay for antioxidant activity analysis. Analytical Sciences, 34(7), 795-800. DOI:10.2116/analsci.18P014

Ślesak, I., Kula, M., Ślesak, H., Miszalski, Z., \& Strzałka, K. (2019). How to define obligatory anaerobiosis? An evolutionary view on the antioxidant response system and the early stages of the evolution of life on Earth. Free Radical Biology and Medicine, 140, 61-73. DOI:10.1016/j.freeradbiomed.2019.03.004

Soares, G. P. A., Souza, K. S. T., Vilela, L. F., Schwan, R. F., 
\& Dias, D. R. (2017). $\gamma$-decalactone production by Yarrowia lipolytica and Lindnera saturnus in crude glycerol. Preparative Biochemistry and Biotechnology, 47(6), 633637. DOI:10.1080/10826068.2017.1286601

Soong, J. L., Fuchslueger, L., Marañon-Jimenez, S., Torn, M. S., Janssens, I. A., Penuelas, J., \& Richter, A. (2020). Microbial carbon limitation: The need for integrating microorganisms into our understanding of ecosystem carbon cycling. Global Change Biology, 26(4), 1953-1961. DOI:10.1111/gcb.14962

Sugibayashi, K., Yusuf, E., Todo, H., Dahlizar, S., Sakdiset, P., Arce, F. J., \& See, G. L. (2019). Halal cosmetics: A review on ingredients, production, and testing methods. Cosmetics, 6(3), 1-17. DOI:10.3390/cosmetics6030037

Suh, M., Proctor, D., Chappell, G., Rager, J., Thompson, C., Borghoff, S., Finch, L., Ellis-Hutchings, R., \& Wiench, K. (2018). A review of the genotoxic, mutagenic, and carcinogenic potentials of several lower acrylates. Toxicology, 402, 50-67. DOI:10.1016/j.tox.2018.04.006

Sun, X. M., Ren, L. J., Bi, Z. Q., Ji, X. J., Zhao, Q. Y., Jiang, L., \& Huang, H. (2018). Development of a cooperative two-factor adaptive-evolution method to enhance lipid production and prevent lipid peroxidation in Schizochytrium sp. Biotechnology for Biofuels, 11(1), 65. DOI:10.1186/s13068-018-1065-4

Surya Prakash, D. V., Vangalapati, M., \& Munawar, T. M. (2019). Evaluation of anticancer activity of polyherbal extract of Terminalia chebula, Phyllanthus emblica and Dimocarpus longan on caco-2 colorectal cancer cell lines. International Journal of Innovative Technology and Exploring Engineering, 9(1), 700-706. DOI:10.35940/ijitee.A3942.119119

Trabelsi, L., Chaieb, O., Mnari, A., Abid-Essafi, S., \& Aleya, L. (2016). Partial characterization and antioxidant and antiproliferative activities of the aqueous extracellular polysaccharides from the thermophilic microalgae Graesiella sp. BMC Complementary and Alternative Medicine, 16(1), 1-10. DOI:10.1186/s12906-016-1198-6

Tuttle, A. H., Philip, V. M., Chesler, E. J., \& Mogil, J. S. (2018). Comparing phenotypic variation between inbred and outbred mice. Nature Methods, 15(12), 994-996. Nature Publishing Group. DOI:10.1038/s41592-018-0224-7

Uma Anitha, K. P. G., \& Mythili, S. (2017). Antioxidant and hepatoprotective potentials of novel endophytic fungus Achaetomium sp., from Euphorbia hirta. Asian Pacific Journal of Tropical Medicine, 10(6), 588-593. DOI:10.1016/j.apjtm.2017.06.008

Unsal, V., Dalkran, T., Çiçek, M., \& Kölükçü, E. (2020). The role of natural antioxidants against reactive oxygen species produced by cadmium toxicity: A review. Tabriz University of Medical Sciences, 7(2), 113-117. DOI:10.34172/apb.2020.023

Valentová, K. (2020). Cytoprotective activity of natural and synthetic antioxidants. Antioxidants, 713(9), 13-16. DOI:10.3390/antiox9080713

Wang, L., Du, H., \& Chen, P. (2020). Chlorogenic acid inhibits the proliferation of human lung cancer A549 cell lines by targeting annexin A2 in vitro and in vivo. Biomedicine and Pharmacotherapy, 131, 110673. DOI:10.1016/j.biopha.2020.110673
Wu, Q., Liu, L., Miron, A., Klímová, B., Wan, D., \& Kua, K. (2016). The antioxidant, immunomodulatory, and antiinflammatory activities of Spirulina: an overview. Archives of Toxicology, 90(8), 1817-1840. DOI:10.1007/s00204016-1744-5

Yang, C. S., Ho, C. T., Zhang, J., Wan, X., Zhang, K., \& Lim, J. (2018). Antioxidants: differing meanings in food science and health science. Journal of Agricultural and Food Chemistry, 66 (12), 3063-3068. DOI:10.1021/acs.jafc.7b05830

Yin, Y., Cai, M., Zhou, X., Li, Z., \& Zhang, Y. (2016). Polyketides in Aspergillus Terreus: biosynthesis pathway discovery and application. Applied Microbiology and Biotechnology, 100(18), 7787-7798. DOI:10.1007/s00253-0167733-z

Yukuyama, M. N., Ghisleni, D. D. M., Pinto, T. J. A., \& Bou-Chacra, N. A. (2016). Nanoemulsion: process selection and application in cosmetics - a review. International Journal of Cosmetic Science, 38(1), 13-24. DOI:10.1111/ics. 12260

Zhang, B., Jin, X., Yin, H., Zhang, D., Zhou, H., Zhang, X., \& Tran, L. S. P. (2020). Natural products, traditional uses and pharmacological activities of the genus Biebersteinia (Biebersteiniaceae). Plants, 9(5), 595. DOI:10.3390/plants9050595

Zhao, Y., Guo, L., Xia, Y., Zhuang, X., \& Chu, W. (2019). Isolation, identification of carotenoid-producing Rhodotorula sp. From marine environment and optimization for carotenoid production. Marine Drugs, 17(3), 161. DOI:10.3390/md17030161 